\title{
Study on the Implementation of Interaction Teaching Mode in Distance Education
}

\author{
Chunyu Zhou ${ }^{1} \&$ Zhenhui $\mathrm{Xu}^{1}$ \\ ${ }^{1}$ Applied Technology College, Southwest University of Science and Technology, Mianyang, China \\ Correspondence: Applied Technology College, Southwest University of Science and Technology, Mianyang \\ 621010, China. Tel: 86-138-8112-0316. E-mail: 445935519@qq.com
}

Received: February 21, 2015 Accepted: March 27, 2015 Online Published: September 28, 2015

doi:10.5539/ies.v8n10p158 URL: http://dx.doi.org/10.5539/ies.v8n10p158

\begin{abstract}
By analyzing the learning characteristics of learners and the features of interactive teaching in distance education, this paper proposes the curriculum implementation subject of network education, namely objects multi-directional interaction teaching mode, so as to improve teaching effectiveness and achieve teaching objectives to ensure the quality of teaching, and puts forward some specific implementation measures.
\end{abstract}

Keywords: interactive teaching, mode, adult education

\section{Introduction}

Distance education (network education) in our school is mainly adult education, and the biggest difference between adult education and general education lies in the particularity of the education subject. Subjects of adult education are mature individuals in all aspects who have unique learning characteristics. For example, learners in network education courses have such characteristics as relevant experience of learning, a mature self-concept, a strong awareness of problems and limited learning time. If the adult learning characteristics are ignored or deviated from network education, teaching relationship will be alienated and teaching effectiveness will also be reduced. Hence, the relationship between teachers and students in adult education should not be a controlling relationship but a partnership that jointly creates the meaning of life. Such relationship requires abandoning the traditional teaching methods in adult education. Interactive teaching is a teaching approach that takes into account the interaction between teachers and students to guide students to apply various steps, such as self-questioning, mutual discussion, analysis, summary and presupposition, to regulate and control the process of learning, and to construct the understanding of what they have learned (Du et al., 2007). Interactive teaching emphasizes the full interactive and mutual cooperation between teachers and learners in the teaching process, so it is a suitable teaching method for adult learners.

A learning characteristic based on adult learners will be constructed in course teaching of network education, and interaction teaching mode will also be applied to emphasize the full interaction and mutual cooperation between teachers and adult learners. Interaction teaching mode considers learning characteristics of network learners, and advocates taking measures to solve issues in teaching through mutual cooperation between teachers and students in network education. These advantages of interaction teaching mode help to achieve teaching objectives greatly improve teaching effectiveness of network education and ensure the quality of teaching.

\section{Learning Characteristics of Network Learners}

\subsection{Relevant Experience of Learning}

Most of adult learners in network education are engaging or have engaged in work, and they have rich practical experience and life experience, as well as certain recognition of the relevant knowledge. When understanding new knowledge and new ideas, they will make full use of their original experience to interpret the new knowledge and then to decide whether to accept. In addition, differences in experience among different adult learners or between adult education teachers and adult learners help to achieve experience complementation in classroom teaching, and to offer different perspectives on problems. But, the experience of adult learners is a double edged sword. On the one hand, it promotes their learning; on the other hand, it makes adult learners confine to existing experience and inherent mental models so that they cannot acquire new ideas and new knowledge. 


\subsection{Mature Self-Concept}

Mature self-concept means that physiology, psychology, emotion, social behavior and other aspects can be maintained at a relatively stable state. Adult learners often choose to learn because of their need, so they can decide whether to learn, when to learn and how to learn, and they can be responsible for their own decisions. Generally speaking, adult learners have quite rational ideas and full consideration for their future learning. Once a goal is set, network learners will have aspirations to achieve the goal, and they will also have a great self-control to ensure the realization of the goal. In addition, network learners want others to treat them as mature person. Otherwise, they will have a feeling of being despised.

\subsection{Strong Awareness of Problems}

The main reason why learners participate in network education is that they have encountered some practical problems and confusion in their teaching or daily life. They are difficult to deal with them alone, so they choose to seek help in education. Therefore, adults have a very clear awareness of the problem and a strong desire to solve the problem in the learning process. Unlike students in general education who studies for knowledge reserve, adult learners want to get effect instantly through learning, and hope to improve their abilities to cope and deal with practical problems with the help of adult education teachers.

\subsection{Limited Learning Time}

In many studies on learning disabilities, the "lack of time" is often listed as an important factor that results in the failure of adults' participation in learning. Most network learners play multiple social roles and assume many responsibilities and obligations. Work and life take up a lot of time, so there is a prominent conflict between work and study. They cannot put most of the time and effort into learning but spare some time to participate in the study after work. Therefore, adult learners want to acquire as much knowledge of the needs as possible in the shortest possible time.

\section{Features of Network Interactive Teaching}

Features of network interactive teaching can be concluded to the following four aspects: the harmony of interactive context, the diversity of interactive form, the dynamicity of interactive process and the hierarchy of interactive effects.

\subsection{The Harmony of Interactive Context}

It calls for a harmonious interactive context to achieve effective teaching interaction. With good terms, harmonious relations, less conflict and little psychological distance between teachers and students or between students and students, they have a need and desire to interact with each other. If there is a great psychological distance between teachers and students or between students and students, they will deviate from each other both in attitudes and in interests. Teachers should exchange and communicate more with students through the network to understand the needs of students, and then create a harmonious interactive context according to the actual needs of students.

\subsection{The Diversity of Interactive Form}

In course teaching, interactive subjects mainly are teachers and students, but there are a variety of interactive forms. Interactive forms include the interaction between teachers and students, the interaction between students and students, the interaction between teachers and individual students, the interaction among individual students, the interaction between teachers and the collective of students, as well as the interaction between individual students and the collective of students. And the various forms of interaction are usually fused together in a teaching course. Through teacher-student interaction, teachers can grasp the students' needs and learning situation on the one hand, students can understand the desires and needs of teachers on the other hand, thus enhancing comprehension between teachers and students. Similarly, through student-student interaction, knowing between students and students can be promoted, their friendship be built up, and their spirit of cooperation and mutual assistance be developed.

\subsection{The Dynamicity of Interactive Process}

Course teaching interactive is a dynamic process, and the successful interaction should pursue the realm where teachers and students have clear plans and specific purposes in the interactive process. But due to the dynamicity of the teaching process itself, students may require teachers to meet their own learning needs at any time. At times, students have no desire to interact at the very start, but they spark interest in the interaction because of teachers' prompts or persuasion, and then form the need of interaction. Sometimes teachers originally may not schedule the interaction on a certain teaching content, but they change the established plan and implement 
purposeful interaction according to the actual situation of teaching or students' clear request. Thereby, for one thing, course teaching interactive should have clear plans and specific purposes; for another, teachers should not blindly follow the established program but adapt themselves to changing circumstances and seize the appropriate opportunity to interact with students.

\section{Analysis of the Structural Pattern of Interactive Teaching}

Interaction teaching mode is a classroom teaching mode where students participate in the teaching and also organize the teaching, and teachers play the role of instruction and comprehensive evaluation. Interactive teaching philosophy has long been popular in foreign countries. It has gradually evolved into a teaching mode in the long-term development. After being introduced to China, interaction teaching mode is mainly applied in higher vocational education and seldom applied in other forms of education. However, the construction of interaction teaching mode is based on the characteristics of adult learning. It advocates taking measures to solve problems in teaching and achieve teaching objectives through mutual cooperation between teachers and students in adult education.

Structural patterns of interactive teaching have been changing and developing through the following evolution process (Owen \& Demb, 2004): one-way interactive mode; two-way interactive mode; double-subject interactive mode; design-participation-evaluation-reflection mode; subject-object multi-directional interactive mode.

By analyzing the pros and cons of the above-mentioned five interaction teaching modes and combining the learning characteristics of network learners in course learning process, it is concluded that the most ideal interactive mode in online course teaching should be subject-object multi-directional interactive mode. In this structural pattern of interactive teaching, as double subjects of the teaching, teachers and students not only interact with each other, but also interact with teaching objects respectively. Moreover, they also complete the self-interaction. Teachers and students keep a democratic, equal, harmonious state in this structural pattern of interactive teaching $(\mathrm{He}, 1997)$. The teacher no longer considers himself to be an absolute leader who requires students to ponder over his thoughts. For students, teachers are not terrifying anymore; instead they are the guide, organizer and collaborator in the entire process of classroom teaching. By means of an equal status, teachers communicate with students and encourage students to think independently so that students can get more opportunities to participate in interaction. Meanwhile, the time of interaction is flexible. Thus, in course teaching activity, the interaction between teachers and students or between students and students can be conducted in a relaxed, unconstrained state. During the interaction, through the constant guidance of teachers, students take the initiative to explore, boldly raise doubts, actively carry out discussion, and dare to make innovation and present their own views to teachers and students. Teachers can work together with students to carry out more in-depth study of curriculum knowledge, and can guide and help students resolve difficulties encountered in the process of independent thinking. This interactive mode of course teaching give full play to the subjectivity of students by promoting and encouraging students to learn and think independently. Consequently, students' enthusiasm and interest in learning have been greatly improved. In addition, this interactive mode reflects student-oriented educational philosophy that teachers act as the organizer, guide and collaborator of course teaching. Therefore, it not only contributes to the development of course teaching interaction, but also helps to improve teaching efficiency.

\section{Implementation Measures of Interactive Mode}

\subsection{Teaching Preparation}

The advanced and two-way transmission of teaching information has a major impact on the quality of teaching. The advanced and two-way transmission of information about network learners and network education teachers not only contributes to a good teaching preparation, but also constitutes the prerequisite and basis for the interaction between learners and teachers. If adult learners are informed of the details of teaching in advance, they will make full preparations for their learning and enter into the learning state early. Likewise, if network education teachers are aware of the learning motivation and desire of adult learners, they may know how to take measures to meet the individual needs of the curriculum. Information can be transmitted in way of "Information Sheet of Network Education Teachers" and "Information Sheet of Network Learners" or by means of other communication ways, such as consultation conference, telephone, Email, BBS, micro-blog, etc.

\subsection{Teaching Implementation}

The core and soul of network interaction teaching mode is that network learners actively participate in the teaching process. Students are educatee, but in specific scene of teacher-student interaction students will actually become "non-educatee", and they may actually act as "educators". In the process of interactive teaching, the 
"teach" of network education teachers and the "learn" of network learners should be completely fused together. The entire teaching process is a co-construction and mutual promotion process between teachers and students or between students and students. The emphasis on network learners' dominant position encourages adult learners to participate in the teaching process, and effectively resists the teaching method of forced indoctrination. Adult learners have the capital (namely their experience) and abilities (namely the self-concept) to participate in the teaching process, and they have a desire to interact (namely their consciousness of problems). Therefore, the interaction in teaching between network learners and network education teachers is feasible and necessary. In addition, although adult education teachers and adult learners have different responsibilities and obligations, they share the same goal, that is, the realization of course objectives. This is also an important reason for the implementation of network interaction teaching mode. The perfect state of adult interaction teaching mode is that teachers and students take subject knowledge as the theme and apply previous work and learning experience to promote the free flow of effective information in an equal and trustful environment. In the interaction, adult learners and adult education teachers fully draw insights and perspectives of others and deepen the understanding of knowledge, so as to enrich and improve their knowledge structure.

\subsection{Teaching Evaluation}

Teaching evaluation of interaction teaching mode which is reached by common reflection belongs to process evaluation and internal evaluation. It takes the improvement of teaching process as the direct guidance so that it can effectively implement the evaluation function and reduce evaluation costs. It includes the self-assessment based on self-reflection and the mutual evaluation based on common reflection, and advocated that self-assessment and mutual evaluation should be combined together and run throughout the entire teaching process. Self-reflection originates from the doubt and confusion arising from the context of direct experience. Common reflection is established on the basis of self-reflection; teachers and students exchange and discuss the results of self-reflection, and break the limitations of self-reflection to conduct a multi-angle and multi-dimensional exploration of problems (Jin, 2006). The course objective is an important basis for the evaluation of teaching. In an interactive teaching, network education teachers and network learners have the opportunity to make common reflection and check if course objectives that they make together have been realized. For course objectives that have not been realized, they can carry out a further reflection to find out the reason. Are presupposed course objectives unreasonable, or is there any flaw in the teaching process, or is it affected by the external environment? Adult education teachers and adult learners can reflect on the behavior and improvement of others, and accordingly make their own evaluation (Hamilton, 2004). When common reflection is penetrated in the teaching activities, it will have a strong real-time feedback that helps adult education teachers and adult learners know the gap between the "self" and "alter ego". Through the contemplation and supervision of others, the "self" will be inspired constantly, and finally network education teachers and network learners will adjust their teaching and learning.

Certainly, there are some problems and deficiencies in network interaction teaching mode. For example, the quality requirement for network education teachers are demanding, and network education teachers should properly handle the relationship with the curriculum goals and adult learners. Besides, teaching objectives in network interaction teaching mode are set in advance, and in the teaching process adult education teachers and adult learners cannot change them but try to achieve the objectives by constantly adjusting teaching activities. Once teaching objectives are set unreasonably, it will bring a lot of problems to the whole teaching and learning process. In conclusion, the network interaction teaching mode is a process of spirit encounter and experience sharing between adult education teachers and students. Taking the language as an intermediary, network education teachers and students reach mutual understanding through dialogue to realize the fusion of different horizons between teachers and students or between students and students. In doing so, a relationship of cooperation and co-construction between teachers and students will finally be established.

\section{References}

Du, Y., Yao, Y., \& Li, X. (2007). Discuss on the Development of Adult Education. Beijing: China.

Hamilton, D. (2004). When Performance Is the Product: Problem in the Analysis of Online Distance Education. British Educational Research Journal, 30(6), 849. http://dx.doi.org/10.1080/0141192042000279530

He, K. (1997). Teaching Mode, Teaching Methods and Teaching Design of Constructivism. Journal of Beijing Normal University (Social Science Edition), 5.

Hong, M. (2008). The design of interactive mode in network teaching. Software Guide, 3.

Jin, Y. (2006). Reflection on Teaching. Sichuan. China 
Meng, X. (2013). Exploration of the teaching mode of design and practice of network course based on the network curriculum. China Distance Education, 11.

Owen, P. S., \& Demb, A. (2004). Change Dynamics and Leadership in Technology Implementation. The Journal of Higher Education, 75(6), 636-666. http://dx.doi.org/10.1353/jhe.2004.0037

Zhang, C., \& Wu, Y. (2011). Research on Interactive Teaching in Modern Distance Education.

Zhu, X. (2007). The analysis of network interactive teaching mode based on Web. Distance Education Journal, 3.

\section{Note}

This article is one of the achievements of Southwest University of Science and Technology to continue education research and development fund in 2012 project. (Serial number: 12JYF05)

\section{Copyrights}

Copyright for this article is retained by the author(s), with first publication rights granted to the journal.

This is an open-access article distributed under the terms and conditions of the Creative Commons Attribution license (http://creativecommons.org/licenses/by/3.0/). 